\title{
Índices de Eficácia e Eficiência para a Política Monetária: Uma análise do desempenho brasileiro nas Metas de Inflação
}

\author{
Ricardo Aguirre Leal* \\ Flávio Tosi Feijó**
}

\begin{abstract}
Resumo: O presente estudo teve o objetivo de avaliar e quantificar o desempenho da política monetária brasileira no regime de Metas de Inflação, utilizando Indicadores de Eficácia e Eficiência, o que pode ser considerado uma nova metodologia para avaliação de política monetária. Ao final concluiu-se que a política monetária, ao longo dos doze anos completos de Metas de Inflação, foi ineficaz em quatro anos do período e ineficiente em cinco anos, ao passo que a meta da inflação não foi atingida apenas em três anos do período.
\end{abstract}

Palavras-chave: Política Monetária; Metas de Inflação; Eficácia; Eficiência.

Classificação JEL: E52; E31; E58.

* Mestre em Economia Aplicada - PPGOM/UFPel.

** Professor Associado - Universidade Federal do Rio Grande do Sul - UFRGS Doutor em Economia Aplicada - PPGE/ UFRGS. 


\section{Introdução}

A teoria concernente à curva de Phillips relaciona negativamente a inflação e o desemprego, proporcionando às autoridades monetárias, desprovidas de limites restritivos, um trade-off entre estas variáveis, na forma de ajustes econômicos discricionários. Os pensadores novo-clássicos asseguram que, devido à curva de Phillips, há um viés inflacionário, uma tendência a gerar inflação, presente nas economias sem tecnologias de comprometimento (restrições à discricionariedade) para as autoridades monetárias. Em decorrência, o conhecimento do viés inflacionário por parte dos agentes privados, possuidores de expectativas racionais, em certos contextos os fazem acreditar em uma inflação futura maior que a inflação presente. Suas expectativas passam a refletir no nível geral de preços por meio dos reajustes salariais e de preços dos produtos ao anteverem o futuro.

O Brasil, atualmente aquiescente dessa teoria, aderiu ao regime monetário de metas de inflação em 1999, como forma de estratégia políticomonetária no controle dos preços, condutora das expectativas dos agentes ao nortear a formação dos preços na direção indicada pela autoridade monetária, através de uma âncora nominal que consiste na própria taxa de variação dos preços. Isso se deu inclusive por já haver uma consciência econômica brasileira de que a estabilidade é um fator essencial para o crescimento sustentável e o desenvolvimento do país.

O foco do presente trabalho é exatamente essa estratégia monetária, utilizada pelo Brasil a partir de 1999 na manutenção da estabilidade econômica, então já conquistada pelo país, decorrente da implantação do Plano Real em 1994, em conjunto com a âncora cambial. Neste sentido, busca-se, num esforço metodológico, avaliar o desempenho da política monetária brasileira no regime de metas de inflação a partir da adoção desta âncora monetária após a flutuação cambial de 1999, contudo sem ter como parâmetro de referência o período anterior do regime cambial, mas sim a referência do que foi definido como ideal para a política monetária brasileira no momento do anúncio da nova âncora. A avaliação foi realizada para o período de 2000 a $2011^{1}$.

\section{Metodologia}

Para a elaboração da metodologia, utilizou-se o referencial teórico exposto em Garcia (2001), o qual julga que o processo de avaliar “[...] não significa apenas medir, mas, antes de mais nada, julgar a partir de um referencial de valores. É estabelecer, a partir de uma percepção intersubjetiva e valorativa, com base nas melhores medições objetivas, o confronto entre a situação atual com a ideal'(Garcia, 2001, p. 30, grifo nosso). Segundo o mesmo autor, também é fundamental dispor-se de clareza para a percepção do valor determinado como

\footnotetext{
1 O ano de 1999 não foi incluído devido ao fato de não ter sido englobado completamente pelo regime de metas de inflação.
} 
meta, de forma a se ter subsídios para criar parâmetros de referência para a avaliação.

De acordo com o exposto, para o intento deste trabalho (avaliação da política monetária) é necessário primeiramente conhecer o seu valor determinado como meta, o seu objetivo, ou seja, o resultado da otimização (o ideal) da funçãoobjetivo.

Cabe lembrar que em junho de 1999 o então Ministro da Fazenda Pedro Malan, no seu pronunciamento de anúncio das metas de inflação e na justificativa destas, expôs que o objetivo principal da política monetária é a estabilidade dos preços, não como objetivo único, mas como primordial e de condição necessária para o alcance dos outros - a supremacia da estabilidade (Malan, 1999).

Nesse sentido, foram utilizadas, como parâmetro de referência para a avaliação, as metas de inflação definidas pelo CMN, que foram, e são, realmente os valores determinados como meta. Elas podem ser consideradas os ótimos pontuais da função-objetivo da política monetária brasileira, desde que sejam considerados os seus objetivos secundários, como a maximização do emprego e da produção, pois também foram definidos como objetivos pelo Ministro da Fazenda em 1999, contudo condicionados à estabilidade. É importante ressaltar que Malan (1999) não citou explicitamente os objetivos de emprego e produção, contudo, deixou claro implicitamente que, no mínimo, estes faziam parte dos objetivos secundários à estabilidade dos preços. Utilizar-se-á, como suposto desta avaliação, que a função-objetivo da política monetária brasileira é prioritariamente a estabilidade de preços, acompanhada da maximização do emprego e da produção. E, em consequência do emprego das metas de inflação como parâmetro de referência, se empregará o horizonte de referência da meta, que é de um ano, para definir os períodos parciais a serem avaliados.

De volta ao artigo de Garcia (2001), este cita que para a criação dos processos avaliativos utilizam-se indicadores, passíveis de monitoramento visual direto, que indiquem as alterações expressivas das variáveis técnicas e relevantes. Dessa forma, sintetizam-se grandes quantidades de informações primárias em uma pequena informação relevante, através da conversão dos registros básicos em indicadores e sinais, servindo à avaliação do programa governamental e aos posteriores processos de decisão relativos à gestão do programa.

$\mathrm{Na}$ avaliação da qualidade (ou desempenho) da ação governamental (no caso do estudo de Garcia (2001) - caráter fiscal), referente ao compromisso assumido e anunciado do programa, é necessário definir quais os aspectos desse desempenho que serão relevantes ao processo avaliativo, sem a imperiosidade da exaustão dos aspectos, possuindo, contudo, um mínimo comum a ser levantado para a avaliação das ações. Conforme a definição de Garcia (2001, p. 40, grifo nosso),para fins de avaliação das ações governamentais, "[...]desempenho é resgate do compromisso de execução de uma programação formalmente estabelecida como desejável e factível, a partir de parâmetros confiáveis surgidos da aplicação do conhecimento técnico-científico sobre a experiência prática".

Com essas definições, o autor propõe que a avaliação de desempenho 
tenha como referência a busca pela eficácia e eficiência, pois, "o bom governo é o que faz o que anuncia, no prazo certo, com a melhor qualidade, para o maior número de pessoas, ao menor custo possível" (Garcia, 2001, p. 40-41). E, para tal, propõe os seguintes conceitos de eficácia e eficiência, com o fim de determinar a sistemática de avaliação das ações governamentais:

a) Eficácia -“[...] é o grau em que se atingem os objetivos e as metas de uma ação orientada para um alvo particular, em um determinado período de tempo, independentemente dos custos nos quais se incorra" (Garcia, 2001, p. 42, grifo nosso); e

b) Eficiência - "[...] é a relação existente entre os produtos resultantes da realização de uma ação governamental programada e os custos incorridos diretamente em sua execução" (Garcia, 2001, p. 43, grifo nosso).

$\mathrm{Na}$ definição apresentada de eficácia destacam-se as variáveis meta e tempo, na eficiência inclui-se a variável custo. As relações entre essas variáveis permitem avaliar o desempenho da ação governamental.

Para o cálculo do grau que foi atingido de eficácia, Garcia (2001) indicou a fórmula proposta por Orozco (2000), tal como se segue:

$$
E a=\frac{\frac{M_{r}}{T_{r}}}{\frac{M_{p}}{T_{p}}}=\frac{\frac{M_{r}}{M_{p}}}{\frac{T_{r}}{T_{p}}}=\frac{M_{r} T_{p}}{M_{p} T_{r}}
$$

onde:- $E a$ = eficácia;

- $M_{r}=$ unidades realizadas da meta programada;

- $M_{p}=$ meta programada;

- $T_{r}=$ tempo real gasto para a realização das unidades da meta; e

- $T_{p}=$ tempo planejado para se realizar a meta total.

O resultado de deve ser interpretado da seguinte forma:

a) se $E a>1$, a ação é mais do que eficaz;

b) se $E a=1$, a ação é eficaz; e

c) se $E a<1$, a ação é ineficaz.

E para a eficiência utilizou a seguinte fórmula, com resultado interpretado de forma análoga à:

$$
E e=\frac{\frac{M_{r}}{T_{r} C_{r}}}{\frac{M_{p}}{T_{p} C_{p}}}=\frac{\frac{M_{r}}{M_{p}}}{\frac{T_{r} C_{r}}{T_{p} C_{p}}}=\frac{M_{r} T_{p} C_{p}}{M_{p} T_{r} C_{r}}=E a \frac{C_{p}}{C_{r}}
$$

onde:- $E e=$ eficiência;

- $C_{r}=$ custo real da ação; e

- $C_{r}=$ custo programado da ação;

Voltando-se novamente ao escopo monetário, uma consideração importante a ser feita a respeito da aplicação é a questão dos aspectos de desempenho relevantes à avaliação. Garcia (2001) definiu as variáveis meta e tempo como os aspectos de desempenho para o indicador eficácia; meta, tempo e 
custo para a eficiência. Sobre a meta na presente aplicação, ficou configurada como sendo a inflação para cada período de horizonte de referência da meta. Agora, sobre o tempo, cabe ressaltar que o autor faz menção à avaliação de programas governamentais temporalmente programados, mas não de intervalos discretos, possuindo programação e não limite de tempo. Contudo, para o presente caso, já que se avaliará a política monetária em períodos parciais e não como um todo, a ação da autoridade monetária no alcance da meta é condicionada ao horizonte de referência da meta, sem a possibilidade de atraso no cumprimento da meta, pois findo o período parcial, também acaba a ação da autoridade monetária referente àquele período, encerrando, dessa forma, os dados relativos à avaliação parcial. Sendo assim, o tempo efetivo (realizado) será sempre igual ao programado e não fará sentido incluir essa variável como um aspecto de desempenho para a avaliação. Por isso, o tempo não será incluído no cálculo da eficácia e eficiência da política monetária.

Ainda sobre o tempo, para as ações governamentais mencionadas por Garcia (2001), percebe-se que este é relevante ao processo avaliativo, pois a qualidade/desempenho da ação difere para distintos valores da variável, tanto para julgamentos subjetivos quanto objetivos. Seguindo o raciocínio, inclui-se na avaliação monetária não o tempo, já visto sem sentido para esta aplicação, mas a taxa de juros nominal de curto prazo, que é a meta operacional do modus operandi brasileiro no regime de metas de inflação, e um aspecto de desempenho relevante ao processo avaliativo, pois é variável intrinsecamente ligada ao objetivo, à meta inflacionária - e o desempenho da autoridade monetária também difere para distintos valores da taxa de juros. Adiante justifica-se melhor a utilização da taxa de juros. Resumindo, para este trabalho serão usadas as metas inflacionárias e as taxas de juros como os aspectos de desempenho necessários ao cálculo do indicador de eficácia.

Sobre a eficiência, Garcia (2001, p. 43-44, grifo nosso) explica que, para o método sugerido no artigo, como "[...] se adotou um conceito reducionista da ação governamental, igualando-a aos projetos e atividades orçamentórios com destinação finalista, fica assegurado que todos os insumos necessários à produção das ações terão expressão monetária". Ou seja, para o método sugerido por Garcia, utilizam-se os insumos tempo e capital para atingir a meta - há um trade-off do tipo "tempo/capital vs meta". E considera-se como custo apenas o insumo capital. Contudo, para essa aplicação, torna-se inviável quantificar os custos em expressões monetárias, tal como faz Garcia para as atividades fiscais. No entanto, utilizar-se-á para o custo, sem expressão monetária, variáveis dependentes do nível da taxa de juros - isso justifica a troca do aspecto tempo pela taxa de juros, visto que esta é o único "insumo" concreto da política monetária brasileira para maximizar a sua função-objetivo². Portanto, os custos incorridos na busca pela meta inflacionária derivam, neste modelo, necessariamente da taxa de juros. Como esta não configura diretamente um custo à sociedade, há de se extrair dela as consequências desfavoráveis relativas à sua aplicação.

2 Deve-se lembrar que o Brasil adotou como meta operacional a taxa de juros, e não as reservas bancárias para se atingir as metas intermediárias e final, conforme o modus operandi de um regime de metas de inflação. Ver Leal (2010). 
A partir do modelo IS-LM, sabe-se que a taxa de juros (i) é negativamente relacionada com o produto ( $Y$ ). Ceteris paribus, uma $\downarrow i$ causa $\uparrow Y$; e um $\uparrow i$ causa $\downarrow Y$. Através da relação de oferta agregada (OA) também se sabe que o produto é negativamente relacionado com o desemprego $(u)$. Ou seja, ceteris paribus, se $\uparrow Y, \downarrow u$, e vice-versa. Dessa forma, pode-se adotar como custos ao processo avaliativo, decorrentes de um aumento na taxa de juros com vistas a diminuir a inflação, a queda da produção e o aumento do desemprego.

É bem verdade que diversas outras variáveis também podem ser elencadas como afetadas pela taxa de juros, assim como também poderíamos adotar o investimento (decréscimo) como custo; contudo, é importante lembrar que, para julgar, é necessário haver um referencial de valor, com o qual irá se confrontar a situação atual com a ideal. Ou seja, para esse tipo de processo de avaliação existe a condição de que haja uma meta (programação) para a variável, uma situação ideal, desejada, factível e, principalmente, mensurável. $\mathrm{E}$ o produto e o desemprego possuem essas características. Por isso definiu-se estes como os custos da avaliação, ainda que discricionariamente, mas também porque são eles os alvos utilizados comumente nos trade-offs monetários. Deve-se lembrar, também, de que não é forçoso esgotar todos os aspectos de desempenho relevantes ao processo avaliativo, sendo necessário apenas um mínimo comum a ser utilizado na avaliação (Garcia, 2001).

Também decorrente dessas questões, a utilização do insumo e a aceitação dos custos nos seus níveis programados não são garantia de cumprimento da meta, ou seja, não há uma relação estática entre inflação e juros, juros e produto e também produto e desemprego. Isso ocorre porque outras variáveis exógenas ao modelo podem afetar as relações entre estas. Assim, devido à enorme complexidade do mundo real, dificilmente serão proporcionais as razões programada e efetiva, presentes nas fórmulas de eficácia e eficiência, sendo possível tal feito somente se fossem tornadas endógenas todas as inúmeras variáveis relacionadas ao modelo, como numa regressão perfeita, algo pouco possível de ser realizado em tão complexa dinâmica. Contudo, não é isso que se deseja, mesmo porque tal realização, tornando proporcionais as razões programadas e efetivas, faria os resultados de e sempre iguais a 1, e tiraria o sentido da avaliação.

Diante disso, forçoso se faz retomar a ideia de avaliação. Como já citado, na avaliação se impetra "[...] a quantidade de um valor desejado nos resultados de uma ação empreendida para obtê-lo" (Garcia, 2001, p. 31). Destarte, para os fins deste trabalho, poder-se-ia definir a eficiência da política monetária no regime de metas de inflação, ou a eficiência monetária, como "a relação entre o grau em que o Banco Central atinge a meta de inflação, e o nível de desemprego e produção resultantes deste processo, com fins à estabilidade econômica, por meio de determinado nível de juros em um ano definido". Contudo, foi visto que o resultado não expressa somente o quão perto se chegou da meta inflacionária - isso poderia ser feito apenas comparando a inflação efetiva com a meta. Os resultados buscam verificar se as razões inflação-juros e inflação-juros-produtodesemprego realizadas foram melhores $(>1)$, piores $(<1)$ ou tão boas $(=1)$ quanto 
aquelas programadas ${ }^{3}$, independentemente do quão perto se chegou da meta. Ou seja, se avalia o desempenho da taxa de juros, e não estritamente do BC, em alcançar a meta inflacionária. E, como a taxa de juros representa o canalizador operacional da política monetária brasileira, e esta compartilha dos mesmos objetivos do modelo, estamos avaliando, por fim, a própria política monetária. Assim sendo, atribuem-se novos sentidos ao processo avaliativo por meio de $E a$ e Ee, que serão adotados, daqui em diante, conforme os formatos apresentados a seguir:

a) indicador de eficácia monetária $(\stackrel{m}{E a})$ : avalia o desempenho da política monetária brasileira em atingir a meta de inflação - indica o grau de desempenho; considera-se este:

$$
\begin{array}{ll}
\text { - eficaz: } & \text { se }\left(\begin{array}{c}
m \\
E a
\end{array}\right) \geq 1 \\
\text { - ineficaz: } & \text { se }\left(\begin{array}{c}
m a \\
E a
\end{array}\right)<1
\end{array}
$$

b) indicador de eficiência monetária $\stackrel{(m}{E e})$ : avalia o desempenho da política monetária brasileira em atingir a meta de inflação com o maior nível de produção e emprego possivel-indica o grau de desempenho; considera-se este:

- eficiente: $\quad$ se $(\stackrel{m}{E e}) \geq 1$

- ineficiente: se $(\stackrel{m}{E e})<1$

Observe que o indicador de eficiência monetária avalia exatamente os resultados da função-objetivo da política monetária definida por este trabalho, ou seja, avalia o alcance dos objetivos definidos pelo ministro Pedro Malan, quando do anúncio das metas de inflação, considerando que os objetivos secundários à estabilidade da inflação citados por ele sejam apenas o alto nível de produção e emprego.

\section{Construção dos indicadores}

De acordo com a estrutura proposta por Orozco (2000) e Garcia (2001) para 1 e 2, pode-se elaborar as equações para a política monetária através dos conceitos vistos a pouco. Assim, a eficácia monetária é configurada conforme se segue:

$$
\stackrel{m}{E a_{t}}=\frac{\pi^{p}}{\pi} \cdot \frac{i^{p}}{i}
$$

$$
\begin{aligned}
\text { onde:- } & \stackrel{m}{E a_{t}}=\text { eficácia monetária no ano } \mathrm{t} ; \\
& -\pi^{p}=\text { inflação programada para o ano } \mathrm{t} ; \\
& -\pi=\text { inflação efetiva no ano } \mathrm{t} ; \\
& -i^{p}=\text { taxa de juros programada para o ano } \mathrm{t} ; \\
& -i=\text { taxa de juros efetiva no ano } \mathrm{t} ;
\end{aligned}
$$

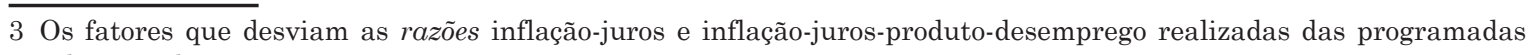
podem ser diversos. 
Denominou-se a proporção entre o valor programado e o efetivo de cada aspecto de desempenho como razão de aspecto. A interpretação é simples: o quanto do valor programado do aspecto foi efetivamente atingido, independentemente de qualquer outro. Sendo, por exemplo, a razão do aspecto inflação denominada de razão de inflação, que expressa se foi ou não atingida a meta de inflação (valor 1), e em que grau isso ocorreu.

No modelo de Orozco (2000) (1) a razão da meta é entre a realizada e a programada, já para o presente modelo (3) a razão é entre a programada e a realizada. A inversão é necessária porque os sentidos também o são: para o primeiro modelo, quanto menor for o valor da variável efetiva $\left(M_{r}\right)$, pior o resultado; para o presente modelo, quanto menor for o valor da inflação efetiva $(\pi)$, melhor. Esta interpretação também é utilizada para definir o sentido da razão nas outras variáveis.

Sendo assim, definiu-se a inflação programada como uma inflação constante, mantenedora da estabilidade econômica, e de valor definido para cada período por meio da meta de inflação, deliberada pelo CMN geralmente em $t$-2. De acordo com os supostos do tripé das metas de inflação, extraem-se algumas deduções. $\mathrm{Na}$ situação descrita (inflação constante), o desemprego se encontra no seu nível natural, na chamada $N A I R U$ - a taxa de desemprego que mantém a inflação constante, por meio do equilíbrio no mercado de trabalho ${ }^{4}$. Por conseguinte, é também a situação que descreve o nível natural de produto (ou produto potencial), "[...] o nível de produto associado à taxa natural de desemprego" (Blanchard, 2007, p. 285) e à inflação constante. A taxa natural de juros (ou taxa de juros de equilíbrio) também se faz presente aqui, que é igualmente definida como a taxa de juros real que mantém a inflação constante. A variável inflação efetiva dispensa comentários.

A taxa de juros programada é aquela que, quando usada, torna a inflação igual à inflação programada. De acordo com o mencionado a pouco, é a taxa natural de juros $\left(r^{n}\right)$. Porém, como esta refere-se ao seu valor real e trabalha-se aqui com valores nominais, é adicionada a variação dos preços, por meio da meta de inflação, de forma que ela represente a taxa de juros nominal programada. A taxa de juros efetiva, como já visto, representa as taxas de juros nominais que realmente impactaram a inflação efetiva, independentemente do período em que ela foi usada ${ }^{5}$.

Como já descrito, os custos ao processo avaliativo, decorrentes de um aumento na taxa de juros com vistas a diminuir a inflação, são: a queda da produção e o aumento do desemprego. Contudo, deve-se definir quais as razões de aspecto que representarão a queda e o aumento. Se há pouco foi visto que o nível de produção compatível com a inflação programada é o produto potencial $\left(y_{n}\right)$, então a relação a ser definida deve ser entre este e o nível efetivamente realizado, o produto efetivo $(Y)$. Observe que esta relação não trabalha com

4 Ver Blanchard (2007).

5 É importante saber que, como se está avaliando o desempenho para cada período distinto, de um período total discreto (a avaliação não é global), são utilizadas para o cálculo as ações (ajustes na taxa de juros) que refletem os insumos que efetivamente influenciaram o resultado obtido (inflação efetiva), independentemente se as ações foram ou não realizadas no período avaliado. Também são utilizados no cálculo os custos consequentes destas ações que influenciaram o resultado. 
variáveis custo, pois a produção não é um custo, diferentemente do aspecto desemprego, que, por semelhança de ideia, possui relação desemprego natural ( $\left.u_{n}\right)$ /desemprego efetivo $(u)$. Contudo, as soluções das razões de aspecto, definidas como e, podem representar, respectivamente, a queda da produção e o aumento do desemprego, variações derivadas dos ajustes na taxa de juros. Se $y_{n}=y^{p}$ e $u_{n}=u^{p}$, a equação da eficiência monetária toma a seguinte forma:

$$
\stackrel{m}{E e_{t}}=\frac{\pi^{p}}{\pi} \cdot \frac{i^{p}}{i} \cdot \frac{y}{y^{p}} \cdot \frac{u^{p}}{u}
$$

Fazendo...

$$
C T_{t}=\frac{y}{y^{p}} \cdot \frac{u^{p}}{u}
$$

Então...

$$
\stackrel{m}{E} e_{t}=\frac{\pi^{p}}{\pi} \cdot \frac{i^{p}}{i} \cdot C T_{t}
$$

onde:- ${ }^{m} e_{t}=$ eficiência monetária no ano t;

- $y^{p}=$ produção programada para o ano t;

- $y=$ produção efetiva no ano t;

- $u^{p}=$ desemprego programado para o ano t;

- $u=$ desemprego efetivo no ano t; e

- $C T_{t}=$ índice do custo total no ano t.

\section{Obtenção e processamento das informações}

Para ajustar os dados da avaliação do ano $t$ de forma que represente o insumo de $\pi_{t}$, e $u_{t}$ e $y_{t}$ representem os níveis derivados de $i_{t}$, foram utilizados dados trimestrais das variáveis para possibilitar a inclusão das defasagens. Esses dados trimestrais são posteriormente transformados em dados anuais (horizonte de tempo das avaliações) por meio da média aritmética.

São usadas as defasagens da taxa de juros em relação à produção e inflação, conforme indicado pelo Relatório de Inflação do Banco Central do Brasil $^{6}$. A sua defasagem relativa ao desemprego é estimada por este trabalho por meio de uma regressão linear (MQO), comparando os melhores ajustes de defasagem através das informações de Akaike e Schwarz. Supõe-se que as defasagens sejam constantes durante todo o período:

a) taxa de juros $\rightarrow$ produção: 1 trimestre;

b) taxa de juros $\rightarrow$ desemprego: 2 trimestres;

c) taxa de juros $\rightarrow$ inflação: 3 trimestres.

Definidas as defasagens, são apresentadas a seguir as características e

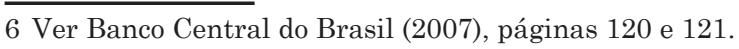


a obtenção dos dados utilizados para as variáveis.

Conforme definido, o parâmetro de referência da avaliação, ou a inflação programada, é a meta de inflação (anual) estipulada pelo CMN. Os valores utilizados no modelo são os limites superiores dos intervalos das metas de inflação definidos para os anos de 2000 a 20117. A opção pelo limite superior justifica-se pelo motivo de não ter sido adotado apenas um ponto focal para a meta de inflação, e sim uma banda de flutuação. E é o limite superior, e não o inferior, que vem historicamente definindo se a meta é atingida ou não.

A inflação efetiva foi obtida pela variação anual do IPCA, de 2000 a

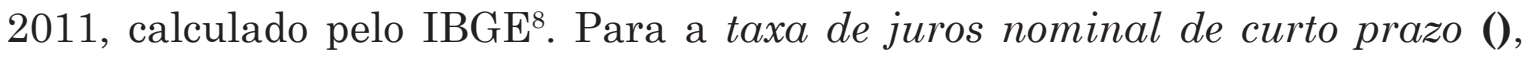
expressa em \% a.a., é empregada no modelo a meta ${ }^{9}$ para a taxa Selic definida pelo Copom ${ }^{10}$.

Para a taxa de juros programada $\left(i^{p}\right)$, primeiramente, calcula-se a taxa de juros natural $\left(r^{n}\right)$, expressa em valores reais, e adiciona-se a variação dos preços (meta de inflação). Optou-se pelo método que também foi utilizado por Del-Vecchio, Alves e Inhudes (2007), que consiste na utilização de equações em diferenças lineares de primeira ordem.

O modelo é o aplicável a períodos discretos, como já visto. Supõe-se, conforme o modelo, que, para um período definido $(t)$, a variável estudada depende dela mesma em seu período anterior $(t-1)$ e também de uma constante (c):

$$
y_{t+1}+a y_{t}=c
$$

$$
\text { onde: } \quad \begin{array}{ll}
-\mathrm{y}=\text { variável estudada; } \\
-a=\text { coeficiente; } \mathrm{e} \\
-c=\text { constante. }
\end{array}
$$

Chiang e Wainwright (2006) explicam que a solução do modelo representa a soma de dois elementos, a solução particular $\left(y_{p}\right)$, representativa de qualquer solução da equação completa não-homogênea (7), e a função complementar ( $y_{c}$ ), representativa da solução geral da equação homogênea conexa a (7): “o componente $y_{p}$ novamente representa o nível de equilíbrio intertemporal de y, e o componente $y_{c}$, os desvios entre a trajetória temporal e esse equilíbrio. A soma de $y_{c}$ e $y_{p}$ constitui a solução geral, por causa da presença de uma constante arbitrária" (Chiang; Wainwright, 2006, p. 527).

Ou seja, através do processo explicado por Chiang e Wainwright (2006) e aplicado por Del-Vecchio, Alves e Inhudes (2007), pode ser obtido o nível de equilíbrio intertemporal da taxa de juros, ou, a taxa natural de juros.

\footnotetext{
7 Para os anos de 2003 e 2004, que tiveram suas metas reajustadas devido às pressões inflacionárias ocorridas a partir de 2002, utilizam-se os limites superiores dos reajustes feitos pelas Resoluções 2.972, de 27/06/2002 e 3.108, de 25/06/2003 do CMN, respectivamente.

8 O IPCA calculado pelo IBGE é o índice de preços definido pelo CMN para o acompanhamento das metas de inflação. 9 Optou-se pela meta e não pela overnight porque é essa a taxa que o BCB decide utilizar para alcançar a meta. Ademais, as diferenças entre elas costumam ser muito pequenas, possibilitando que uma sirva de proxy à outra.

10 A série foi coletada a partir do site do BCB - SGS/Módulo Público, tabela 432, com periodicidade diária. Para fins de utilização no modelo, foi empregada a média trimestral.
} 
Sendo assim, estimou-se uma função autorregressiva para definir a equação (7) e, por conseguinte, o equilíbrio intertemporal da variável - obtevese o valor para a taxa natural de juros, com estabilidade de equilíbrio, de 0,66\% a.m., ou $8,17 \%$ a.a. ${ }^{11}$. Determinado seu valor, construiu-se a série da variável taxa de juros programada $\left(i_{p}\right)$ - como indicado anteriormente, somando $r_{n}$ ao limite superior da meta de inflação.

Feito isso, parte-se para as variáveis desemprego programado $\left(u^{p}\right) \mathrm{e}$ produção programada $\left(y^{p}\right)$. Como visto, para se construir a série $u^{p}$, deve-se calcular a $N A I R U$, já que se fez $u^{p}=u_{n}$; e para a série de $y^{p}$, calcular o produto potencial, pois $y_{p}=y_{n}$.

Foi utilizado para os cálculos de e o filtro de Hodrick-Prescott (filtro $\mathrm{HP}-\lambda$ igual a 1600), que teoricamente extrai da série de dados a sua tendência linear, por meio de uma suavização histórica, separando os dados em um componente de tendência e um componente cíclico. Submetendo estas séries ao filtro HP, foram obtidas as séries de $u_{n}$ e $y_{n}$.

Mediante os resultados dos indicadores, definiu-se dois trimestres (ainda que não exatamente seis meses) de defasagem entre a taxa de juros e o desemprego, ou, entre a taxa de juros efetiva e o desemprego efetivo.

Com a definição da série do desemprego natural e sua defasagem, e também do produto natural, elaboraram-se as séries do desemprego programado $\left(u^{p}\right)$ e efetivo $(\mathbf{u})$, bem como do produto programado $\left(y^{p}\right)$ e efetivo $(\mathbf{y})$.

\section{Sinais numéricos e ícones}

Produziram-se os sinais numéricos da avaliação com os indicadores de desempenho e da política monetária, para cada ano do período de 2000 a 2011 , por meio das equações (3) e (4).

Os resultados obtidos para $E a$ foram impressos na tabela 1, por onde é possível verificar que a eficácia monetária foi maior que um (eficaz) em oito dos doze anos da avaliação, e que os quatro anos de ineficácia correspondem ao período de 2001 a 2004, que englobam algumas das crises econômicas internas e externas. $\mathrm{O}$ ano de 2010 apresentou o maior índice de eficácia (1,76), e o de 2002 o menor $(0,33)$. O gráfico 1 facilita a visualização dos resultados.

Tomando o exemplo do ano de 2004, observa-se que o limite superior da meta de inflação foi de 8,0\% e que a inflação efetivamente ocorrida naquele ano foi $7,6 \%$, fazendo a política monetária vencedora no seu objetivo. Entretanto, com uma taxa de juros programada em 16,17\% para atingir os 8,0\% de inflação, o Banco Central fez uso de $21,20 \%$ de taxa de juros. A taxa efetiva foi mais que proporcional àquela programada para atingir a meta de inflação, apresentando uma razão de juros igual a 0,76 . Isso fez com que a política monetária tenha sido ineficaz, mesmo atingindo a meta de inflação.

11 O cálculo pode ser visualizado em Leal (2010). 
Tabela 1: Eficácia da política monetária

\begin{tabular}{ccccccccc}
\hline Ano & $\begin{array}{c}\text { Inflação pro- } \\
\text { gramada } \pi^{p}\end{array}$ & $\begin{array}{c}\text { Inflação } \\
\text { efetiva }\end{array}$ & $\frac{3}{\pi}$ & $\begin{array}{c}\pi^{p} \\
\text { paxa juros } \\
\text { programada } \\
i^{p}\end{array}$ & $\begin{array}{c}\text { Taxa juros } \\
\text { efetiva } i\end{array}$ & $\frac{i^{p}}{i}$ & $\begin{array}{c}{ }^{m} \\
E a\end{array}$ & $\begin{array}{c}\text { Variação } \\
\text { eficácia } \\
\text { ma }\end{array}$ \\
\hline 2000 & 8,00 & 5,97 & $\mathbf{1 , 3 4}$ & 16,17 & 21,60 & $\mathbf{0 , 7 5}$ & $\mathbf{1 , 0 0}$ & \\
2001 & 6,00 & 7,67 & $\mathbf{0 , 7 8}$ & 14,17 & 16,71 & $\mathbf{0 , 8 5}$ & $\mathbf{0 , 6 6}$ & $-0,34$ \\
2002 & 5,50 & 12,53 & $\mathbf{0 , 4 4}$ & 13,67 & 18,32 & $\mathbf{0 , 7 5}$ & $\mathbf{0 , 3 3}$ & $-0,34$ \\
2003 & 6,50 & 9,30 & $\mathbf{0 , 7 0}$ & 14,67 & 20,96 & $\mathbf{0 , 7 0}$ & $\mathbf{0 , 4 9}$ & 0,16 \\
2004 & 8,00 & 7,60 & $\mathbf{1 , 0 5}$ & 16,17 & 21,20 & $\mathbf{0 , 7 6}$ & $\mathbf{0 , 8 0}$ & 0,31 \\
2005 & 7,00 & 5,69 & $\mathbf{1 , 2 3}$ & 15,17 & 16,88 & $\mathbf{0 , 9 0}$ & $\mathbf{1 , 1 1}$ & 0,30 \\
2006 & 6,50 & 3,14 & $\mathbf{2 , 0 7}$ & 14,67 & 18,82 & $\mathbf{0 , 7 8}$ & $\mathbf{1 , 6 1}$ & 0,51 \\
2007 & 6,50 & 4,46 & $\mathbf{1 , 4 6}$ & 14,67 & 14,27 & $\mathbf{1 , 0 3}$ & $\mathbf{1 , 5 0}$ & $-0,12$ \\
2008 & 6,50 & 5,90 & $\mathbf{1 , 1 0}$ & 14,67 & 11,61 & $\mathbf{1 , 2 6}$ & $\mathbf{1 , 3 9}$ & $-0,11$ \\
2009 & 6,50 & 4,31 & $\mathbf{1 , 5 1}$ & 14,67 & 12,80 & $\mathbf{1 , 1 5}$ & $\mathbf{1 , 7 3}$ & 0,34 \\
2010 & 6,50 & 5,91 & $\mathbf{1 , 1 0}$ & 14,67 & 9,18 & $\mathbf{1 , 6 0}$ & $\mathbf{1 , 7 6}$ & 0,03 \\
2011 & 6,50 & 6,50 & $\mathbf{1 , 0 0}$ & 14,67 & 10,53 & $\mathbf{1 , 3 9}$ & $\mathbf{1 , 3 9}$ & $-0,36$ \\
\hline
\end{tabular}

Fonte: Elaboração própria.

Nota: Os números são valores aproximados. Os cálculos foram feitos com 10 algarismos significativos.

Gráfico1: Eficácia monetária e razão de inflação

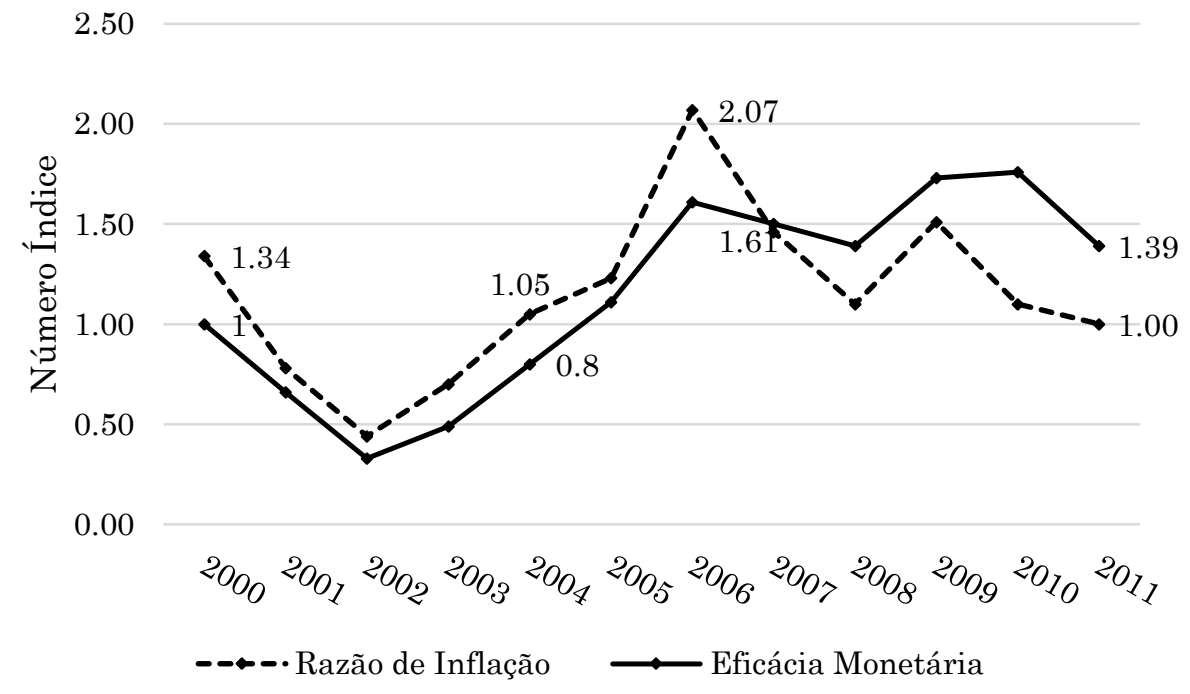

Fonte: Elaboração própria.

Observe-se agora que, do inicio do período até o ano de 2006 (7 anos), a razão de juros esteve sempre abaixo de 1 (tabela 1), contribuindo negativamente para o índice de Ea. Em contrapartida, somente nos de três anos de 2001 a 2003, a razão de inflação esteva abaixo de 1 (não atingimento da meta). No entanto, a partir de 2007 o cenário mudou, pois a taxa de juros (real) empregada 
na economia tem sido mantida abaixo da teórica taxa de juros natural mudança representada no gráfico pelo cruzamento das curvas -, aumentando significativamente os índices anuais de eficácia.

Numa análise gráfica da eficácia monetária (gráfico 1), abstrai-se que somente nos anos de 2001 e 2002 a tendência foi de queda, sendo seguida por tendência altista até 2006. Na continuidade, a eficácia tem-se mantido em um canal de tendência horizontal (sem tendência definida, apesar das variações).

Sobre a eficiência monetária, esta tem seus resultados apresentados na Tabela 2, por onde é possível se conferir que nos anos de 2000 a 2004 a política monetária brasileira foi ineficiente em alcançar o seu objetivo. Como visto há pouco, no ano de 2000, atingiu-se a meta de inflação e foi eficaz, mas, ao contabilizar os custos incorridos, a política monetária se fez ineficiente naquele ano.

Os resultados de $E a$ e $E$ e foram semelhantes, refletindo a pequena variância do índice do custo total ${ }^{12}$ : pela tabela 2 , os resultados desse índice foram sempre próximos de um, demonstrando que os aspectos de custo incluídos no estudo tiveram seus valores efetivos muito próximos dos programados também observável pelo gráfico 3 mais adiante.

Tabela 2: Eficiência da política monetária

\begin{tabular}{|c|c|c|c|c|c|c|c|c|c|c|}
\hline Ano & $\begin{array}{c}\text { Produto } \\
\text { efetivo } \\
y\end{array}$ & $\begin{array}{c}\text { Produto } \\
\text { program. } \\
y^{p}\end{array}$ & $\frac{y}{y^{p}}$ & $\begin{array}{c}\text { Desemp. } \\
\text { program. } \\
u^{p}\end{array}$ & $\begin{array}{l}\text { Desemp. } \\
\text { efetivo } u\end{array}$ & $\frac{u^{p}}{u}$ & $C T$ & $\stackrel{m}{E a}$ & $\stackrel{m}{E e}$ & $\begin{array}{c}\text { Variação } \\
\text { eficiência } \\
\Delta \stackrel{m}{m}^{2}\end{array}$ \\
\hline 2000 & 108,09 & 107,60 & 1,00 & 11,50 & 12,14 & 0,95 & 0,95 & 1,00 & 0,95 & \\
\hline 2001 & 112,00 & 110,39 & 1,01 & 11,41 & 10,29 & 1,11 & 1,12 & 0,66 & 0,75 & $-0,21$ \\
\hline 2002 & 112,47 & 113,29 & 0,99 & 11,38 & 10,89 & 1,05 & 1,04 & 0,33 & 0,34 & $-0,41$ \\
\hline 2003 & 115,77 & 116,55 & 0,99 & 11,31 & 11,78 & 0,96 & 0,95 & 0,49 & 0,47 & 0,13 \\
\hline 2004 & 119,18 & 120,40 & 0,99 & 11,06 & 12,36 & 0,89 & 0,89 & 0,80 & 0,71 & 0,24 \\
\hline 2005 & 125,40 & 124,90 & 1,00 & 10,60 & 10,53 & 1,01 & 1,01 & 1,11 & 1,12 & 0,41 \\
\hline 2006 & 128,69 & 129,97 & 0,99 & 10,02 & 09,71 & 1,03 & 1,02 & 1,61 & 1,65 & 0,53 \\
\hline 2007 & 135,52 & 135,51 & 1,00 & 09,35 & 09,85 & 0,95 & 0,95 & 1,50 & 1,42 & $-0,23$ \\
\hline 2008 & 144,15 & 141,31 & 1,02 & 08,61 & 08,49 & 1,01 & 1,03 & 1,39 & 1,44 & 0,02 \\
\hline 2009 & 145,15 & 147,17 & 0,99 & 07,85 & 08,05 & 0,98 & 0,96 & 1,73 & 1,66 & 0,22 \\
\hline 2010 & 152,89 & 153,21 & 1,00 & 07,06 & 07,47 & 0,95 & 0,94 & 1,76 & 1,66 & $-0,01$ \\
\hline 2011 & 160,43 & 159,42 & 1,01 & 06,25 & 06,24 & 1,00 & 1,01 & 1,39 & 1,40 & $-0,25$ \\
\hline
\end{tabular}

Fonte: Elaboração própria.

Nota: Os números são valores aproximados. Os cálculos foram feitos com 10 algarismos significativos.

Como se percebe, somente para os anos de 2007 em diante, o aspecto taxa de juros influenciou positivamente a eficiência (também a eficácia). Com o aumento dos valores da razão de juros, os efeitos dos ajustes da taxa de juros pelo Banco Central passaram a surtir maior efeito sobre o nível de inflação, dando

12 Para uma curva de tendência linear estimou-se a função $y=0,0027 x+1,0182$, onde 0,0027 é o ângulo da reta. 
ganhos de eficiência e eficácia para o período. Também é evidente a relação dos custos com a taxa de juros, já que esta afeta aqueles.

\section{Gráfico 2: Eficiência monetária e razão de inflação}

$$
2.50
$$

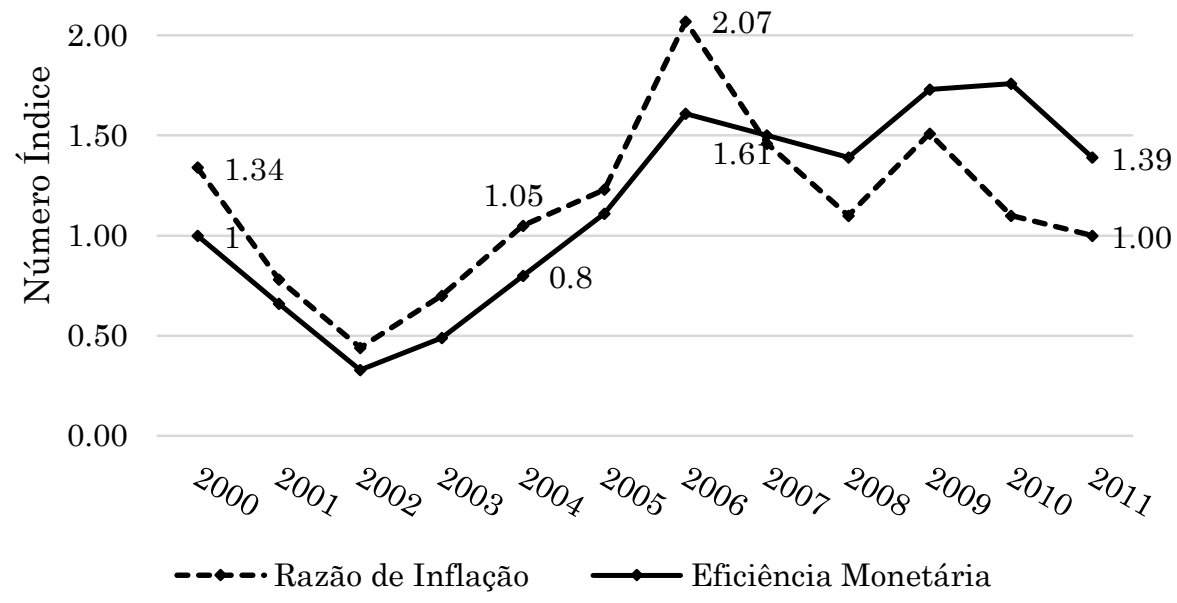

Fonte: Elaboração própria.

A tabela 3 resume o desempenho da política monetária brasileira, de acordo com os indicadores de eficácia e eficiência, por meio de sinais de resultado, incluindo aí um de alcance da meta de inflação, para fins de comparação.

Tabela 3: Resumo do desempenho da política monetária

\begin{tabular}{cccc}
\hline \multirow{2}{*}{ Ano } & Meta de inflação & Eficácia monetária & Eficiência monetária \\
& $\pi^{p} / \pi$ & Ea & Ee \\
\hline 2000 & Atingida & Eficaz & Ineficiente \\
2001 & Não atingida & Ineficaz & Ineficiente \\
2002 & Não atingida & Ineficaz & Ineficiente \\
2003 & Não atingida & Ineficaz & Ineficiente \\
2004 & Atingida & Ineficaz & Ineficiente \\
2005 & Atingida & Eficaz & Eficiente \\
2006 & Atingida & Eficaz & Eficiente \\
2007 & Atingida & Eficaz & Eficiente \\
2008 & Atingida & Eficaz & Eficiente \\
2009 & Atingida & Eficaz & Eficiente \\
2010 & Atingida & Eficaz & Eficiente \\
2011 & Atingida & Eficaz & Eficiente \\
\hline
\end{tabular}

Fonte: Elaboração própria. 


\section{Conclusões}

Conforme os resultados, ajuizou-se o seguinte. A política monetária brasileira teve um desempenho positivo em atingir a meta de inflação em oito dos doze anos completos do regime de metas de inflação. Sendo que a medida deste desempenho é o grau em que se atinge a meta de inflação, por meio de determinado nível de juros, independentemente dos custos envolvidos (Eficácia).

Nota-se também que houve desempenho positivo em atingir a meta de inflação na busca concomitante com o máximo de produção e emprego possível em sete dos doze anos completos de metas de inflação. Sendo esse desempenho medido pela relação entre o grau em que o Banco Central atinge a meta de inflação e o nível de desemprego e produção resultantes deste processo, por meio de determinado nível de juros (Eficiência).

Diante do cálculo do nível de eficácia e, principalmente, do nível de eficiência monetária para os anos de 2000 a 2011, conclui-se que a política monetária brasileira apresentou um desempenho global positivo no regime de metas de inflação, considerando a maximização de sua função-objetivo, conforme definida por este trabalho, ou seja, a busca da estabilidade de preços com o máximo de produção e emprego possível. Também se conclui que a política monetária apresenta um desempenho crescente nos últimos anos, muito favorável à economia brasileira, principalmente a partir de 2007, quando a taxa de juros, o instrumento da política monetária no Brasil, passou a ter maior poder de atuação no controle da inflação.

Outrossim, em decorrência do que foi apresentado à avaliação, o método aplicado não só permitiu julgar o desempenho do período analisado, porém visa propor uma medição objetiva, um índice que dá subsídios ao acompanhamento do desempenho da política monetária para os anos futuros, pois cria um valor único e objetivo para cada ano desejado, capaz de ser comparado e analisado dentro de uma série histórica. Ou seja, um instrumento capacitado a demonstrar a evolução do desempenho da política monetária brasileira incorporada ao regime de metas de inflação. No entanto, como sugestão de aprimoramento do modelo, sugere-se, para uma metodologia mais robusta, a substituição dos cálculos que utilizaram o filtro HP, e do cálculo da taxa de juros natural, por modelos estruturais, mais representativos da realidade, bem como a inclusão de defasagens temporais não-contínuas.

\section{Referências}

Bacen (BANCO CENTRAL DO BRASIL). (2007). Relatório de Inflação, Brasília, v. 9, n. 3, p. 1-165.

Blanchard, O. (2007). Macroeconomia. 4.ed. São Paulo: Pearson Prentice Hall, 602 p.

Carvalho, F. J. C. de; Souza, F. E. P. de; Sicsú, J.; Paula, L. F. R. de; Studart, R. (2007). Economia Monetária e Financeira. 2. ed. Rio de Janeiro: Elsevier. 
Chiang, A. C.; Wainwright, K. Matemática para economistas. 4 ed. Rio de Janeiro: Elsevier.

Del-Vecchio, R.; Alves, J. D. O.; Inhudes, A. (2007). “Taxa de Juros Real de Equilíbrio: Uma análise via equações em diferenças.” In: XXX CNMAC Congresso Nacional de Matemática Aplicada e Computacional. Florianópolis. Não paginado.

Garcia, R. C. (2001). "Subsídios para organizar avaliações da ação governamental." Planejamento e Políticas Públicas. Brasília, n. 23, p. 7-70.

Gujarati, D. (2006). Econometria básica. 4 ed. Rio de Janeiro: Elsevier.

Leal, R. A. (2010). Metas de Inflação no Brasil: análise e avaliação da política monetária. 2010. 122 f. Monografia (Graduação) - Curso de Bacharelado em Ciências Econômicas. Universidade Federal do Rio Grande, Rio Grande, RS.

Malan, P. (1999). "Transcrição do pronunciamento do ministro Pedro Malan ao anunciar as metas inflacionárias para o triênio 1999-2001." Pronunciamentos. Ministério da Fazenda, Brasília. Não paginado

Modenesi, A. M. (2005). Regimes monetários: teoria e a experiência do real. 1. ed. Barueri: Manole, 438 p.

Orozco, C. H. (2000). Planificación y Programación. 1. Ed. San José: EUNED, 225p. 